\title{
A new formulation of graphene oxide/fluconazole compound as a promising agent against Candida albicans
}

\author{
Sabrieh Asadi Shahi ${ }^{1} \cdot$ Shahla Roudbar Mohammadi ${ }^{1} \cdot$ Maryam Roudbary $^{2} \cdot$ Hamid Delavari $^{3}$
}

Received: 31 October 2018 / Accepted: 12 February 2019 / Published online: 11 March 2019

(c) The Author(s) 2019

\begin{abstract}
Candida albicans (C. albicans) belongs to the opportunistic fungal pathogens, which cause a wide spectrum of infections in immune-compromised patients. Graphene oxide (GO), a biocompatibility agent, has been reported to exhibit effective antimicrobial activity. In the present study, a graphene oxide/fluconazole (GO/Flu) compound was synthesized and characterized using Fourier transform infrared spectroscopy (FTIR) and Raman spectroscopy. The antifungal activity of GO/Flu was examined against fluconazole-resistant $C$. albicans (ATCC 10231) compared to GO and Flu using the broth microdilution method, according to CLSI protocol. DNA fragmentation was assessed through the antifungal mechanism of GO/Flu. The release of Fluin PBS medium was measured. Moreover, the cytotoxicity effect of GO/Flu on SW480 cell line was evaluated. Indeed, adhesion ability of $C$. albicans-treated GO/Flu against SW480 cell line was assessed. The minimum inhibitory concentration (MIC) of GO, Flu, and GO/Flu was determined at $800 \mu \mathrm{g} / \mathrm{mL}, 16 \mu \mathrm{g} / \mathrm{mL}$, and 400-9 $\mu \mathrm{g} / \mathrm{mL}$, respectively. Notably, $\mathrm{GO} /$ Flu exhibited an intense antifungal activity compared to GO and Flu. In addition, GO/Flu showed much less cell toxicity against SW480 cell line than GO and Flu $(P<0.05)$. The release determination of Flu in PBS (pH 7.4) medium was $72.42 \%$. $\mathrm{GO} /$ Flu reduced the adhesion ability of $C$. albicans to SW480 cell line significantly. DNA fragmentation assay indicated that GO/Flu potentially degraded the DNA of $C$. albicans and caused a fungicidal influence. According to the findings, GO/Flu could enhance the antifungal activity against $C$.albicans through DNA fragmentation with low cytotoxicity effect.
\end{abstract}

Keywords Antifungal agent $\cdot$ Candida albicans $\cdot$ Graphene oxide $\cdot$ Fluconazole

\section{Introduction}

Candida albicans (C. albicans) is one of the most important opportunistic fungi causing a broad range of diseases from superficial to systemic infections in immunity-compromised

Sabrieh Asadi Shahi

Sabrieh.asadishahi@modares.ac.ir;

sh.mohammadi@modares.ac.ir

Maryam Roudbary

M_roudbary@yahoo.com; roudbari.mr@iums.ac.ir

Hamid Delavari

hamid.delavari@modares.ac.ir

1 Department of Medical Mycology, Faculty of Medical Sciences, Tarbiat Modares University, Tehran, Iran

2 Department of Medical Mycology and Parasitology, School of Medicine, Iran University of Medical Sciences, Tehran, Iran

3 Department of Materials Engineering, Tarbiat Modares University, Tehran, Iran patients (Weber et al. 2008; Khan et al. 2003). Among azole antifungal agents, fluconazole (Flu) is an effective and the most common azole for the treatment of candidiasis. Hence, developing drug-resistant Candida species can lead to serious therapeutic compliance (Charlier et al. 2006). Recent studies reported the intermediate to high incidence of $\mathrm{Can}$ dida spp. resistant to fluconazole (Casalinuovo et al. 2004). It is well known that various molecular mechanisms are responsible for the development of fluconazole-resistant $C$. albicans (Claudia et al. 2010; Kanafani and Perfect 2008; Alizadeh et al. 2017).

Graphene is characterized as carbon atoms closely packed into honeycomb two-dimensional (2D) lattice possessing unique thermal, mechanical, and electrical properties (Allen et al. 2010). Graphene has a specific high surface area and has a great deal of oxygen bonds in its edges and defective sites such as hydroxyl $(\mathrm{C}-\mathrm{OH})$, carboxylic $(\mathrm{COOH})$, carbonyl $(\mathrm{C}-\mathrm{O})$, and epoxide groups $(\mathrm{C}-\mathrm{O}-\mathrm{C})$ accessible on both sides (Stankovich et al. 2007; Haubner et al. 2010). Therefore, graphene due to its potential applications has 
been remarkably used to construct new composites, particularly nanocomposites such as nanoelectronics, conductive thin films, supercapacitors, biosensors, and nanomedicine approaches (Yang et al. 2012; Shen et al. 2012). The number and range of antifungal drugs are limited and the adverse side effects are still a major therapeutic challenge. Therefore, in the last 5 years, the therapeutic application of graphene oxide (GO) due to its drug delivery characteristics has improved (Sawangphruk et al. 2012). Designing drug delivery systems based on nanocompounds is used to overcome the deficits and disadvantages of conventional pharmaceutical formulations, which is done by reducing the frequency and the amount of drug use which increases the drug's effect through focusing on the target site (Chaudhary 2013; Alizadeh et al. 2017). Previous studies reported that GO can inhibit the growth of bacterial cells (Escherichia coli, Staphylococcus aureus) and display superior inactivation effects on copper-resistant bacteria through penetration of GO to bacterial cell membrane (Pasricha et al. 2012; Cong et al. 2010; Liu et al. 2011; Akhavan and Ghaderi 2010). However, prior studies had focused on the antibacterial effect of $\mathrm{GO}$ and few relative reports are available about its antifungal activity. Sawangphruk et al. reported that GO inhibits the mycelial growth of Aspergillus nigger, Aspergillus oryzae, and Fusarium oxysporum (Sawangphruk et al. 2012).

GO has emerged support layers that aid in stabilizing, helping Flu to achieve better controlled release and improved antifungal activity. Therefore, nowadays the design of innovative drug delivery strategies for improving the drug release as a novel approach to combat drug resistance is highly deliberated. In the current study, we synthesized GO/ Flu compound and evaluated the effect of biogenic GO/Flu against $C$. albicans using the antifungal susceptibility test. Besides, we investigated the cytotoxicity effect of GO/Flu compound against SW480 cell line and DNA fragmentation assay. Our results show that the prepared GO/Flu with a lower concentration can be used instead of Flu and GO.

\section{Materials and methods}

(3-Chloropropyl)triethoxysilane (CPTES), fluconazole powder (Flu), dimethylformamide (DMF), chloramphenicol, MTT(3-(4,5-dimethylthiazol-2yl)-2,5-diphenyltetrazolium bromide), dimethyl sulfoxide (DMSO), Dulbecco's modified Eagle Medium (DMEM), dialysis bag (a cutoff of $12,000 \mathrm{Da}$ ) were purchased from Sigma-Aldrich. Sabouraud dextrose agar media (SDA) (Merck, Germany). Microtiter plates (tissue culture grade, 96 wells, flat bottom, Corning, USA). A standard strain of $C$. albicans (ATCC10231) and SW480 cell line were purchased from the cell bank of the Pasteur Institute of Iran.

\section{Preparation of GO}

GO was synthesized using the Hummers' method with a minor modification. An improved Hummers' method without using $\mathrm{NaNO}_{3}$ can produce $\mathrm{GO}$ in nearly the same level as that prepared by the conventional Hummers' method (William et al. 1958).

\section{Structural and morphological characterizations}

The morphological and structural characteristics of GO were determined by Fourier transform infrared spectroscopy (FTIR) (Perkin\&Elmer-Frontier, USA). The thin plate of FTIR samples was prepared by mixing GO powder and potassium bromide $(\mathrm{KBr})$ which was then compressed under high pressure. The FTIR spectra were measured in the range of 500-4000 $\mathrm{cm}^{-1}$. Raman spectra (Almega Thermo Nicolet Dispersive Raman Spectrometer) were recorded in the range of $1000-1700 \mathrm{~cm}^{-1}$ with a laser excitation wavelength of $532 \mathrm{~nm}$.

\section{Synthesis of GO/Flu}

For this purpose, $2.4 \mathrm{mg}$ of $\mathrm{GO}$ was dispersed in $24 \mathrm{~mL}$ toluene through sonication to achieve a homogeneous GO suspension (final concentration is $0.5 \mathrm{mg} / \mathrm{mL}$ ). The UV absorption of the supernatant was studied. (3-Chloropropyl)triethoxysilane (CPTES) (Sigma-Aldrich) was added into the reaction and was sonicated for $30 \mathrm{~min}$. The mixture was heat-treated in an oven at $60{ }^{\circ} \mathrm{C}$ for $6 \mathrm{~h}$. The product was centrifuged at $1000 \mathrm{rpm}$ for $5 \mathrm{~min}$ and washed with methanol twice to remove the impurities. Finally, $\mathrm{GO}-\mathrm{Cl}$ (the free chlorine remaining in the CPTES structure after binding with GO, which contributes to the binding of Flu) was obtained. For the synthesis of GO/Flu compound, $108 \mu \mathrm{g}$ of Flu (Sigma-Aldrich) was added to a GO-Cl suspension prepared in the previous step dispersed in $9 \mathrm{~mL}$ dimethylformamide (DMF) (Sigma-Aldrich). The reaction mixture was refluxed at $140{ }^{\circ} \mathrm{C}$ in an oil bath for $24 \mathrm{~h}$. The solid phase was centrifuged at $1000 \mathrm{rpm}$ for 5 min and washed with DMF. The final product was thoroughly washed with water to reach $\mathrm{pH}$ 7.4.

\section{Confirmation of flu loading on GO-Cl}

The amount of loaded Flu was determined using the standard UV absorption curve in different concentrations of Flu $(1.05-108 \mu \mathrm{g} / \mathrm{mL})$ at $260 \mathrm{~nm}$. Besides, we investigated 
the absorption of GO-Cl-Flu supernatant against GO-Cl supernatant.

\section{In vitro Flu release}

The release rate of Flu from GO/Flu was compared to pure commercial Flu. Separately, for this purpose, $500 \mu \mathrm{L}$ of GO/ Flu $(400 / 9 \mu \mathrm{g} / \mathrm{mL})$ and $500 \mu \mathrm{L}$ of Flu $(9 \mu \mathrm{g} / \mathrm{mL})$ (the initial concentration of Flu in both samples, i.e., pure Flu and GO/ Flu are same as $9 \mu \mathrm{g} / \mathrm{mL}$ ) were released using a dialysis bag (cutoff 12,000 Da, Sigma) in $15 \mathrm{~mL}$ PBS buffer (pH 7.4). At $45 \mathrm{~min}$ interval for every $2 \mathrm{~min}, 1.5 \mathrm{~mL}$ of buffer was removed and its concentration was measured using a spectrophotometer at $260 \mathrm{~nm}$ wavelength. This amount was then re-entered into the original buffer. The release of Flu in PBS (pH 7.4) medium was determined at $72.42 \%$. The experiment was performed at least three times.

\section{Antifungal study}

The minimum inhibitory concentration (MIC) of GO, Flu, and GO/Flu compound was examined using the microdilution broth according to the CLSI method (2002). A standard strain of C.albicans (ATCC10231) was cultured on Sabouraud dextrose agar (SDA, Merck, Germany) containing chloramphenicol (sigma) and was incubated at $35^{\circ} \mathrm{C}$ for $24 \mathrm{~h}$. After that, $1 \times 10^{3} \mathrm{CFU} / \mathrm{mL}$ Candida suspension cell was prepared. Drug susceptibility test was performed in sterile U-bottomed 96-well microtiter plates. For this, 100 Â $\mu \mathrm{l} \mathrm{Flu} \mathrm{(1-128} \mu \mathrm{g} /$ $\mathrm{mL}), \mathrm{GO}(12.5-1600 \mu \mathrm{g} / \mathrm{mL}), 50 \mu \mathrm{L}$ of Flu, and $50 \mu \mathrm{L}$ of GO were added into eight columns and eight rows of microtiter plate at series of concentrations. Also, $100 \mu \mathrm{L}$ of Flu and GO were added separately to each well containing RPMI medium at series of concentrations. Finally, $100 \mu \mathrm{L}$ of yeast suspension was added to each well and were placed on shaker for 3-5 min and were incubated at $37^{\circ} \mathrm{C}$ for $24 \mathrm{~h}$. Each experiment was repeated three times in an independent manner. Moreover, proper positive and negative control was used. The minimum concentration of drug that inhibited the Candida growth was described as MIC.

The minimum fungicidal concentration (MFC) was determined as the minimum concentration of drug that led to death of fungi and followed by culturing fungi on SDA.

FIC $<5$; synergistic effect

$0 / 5<$ FIC $<1$ relative synergistic effect

$\mathrm{FIC}=1$ additive effect

$1<$ FIC $<4$ indifferent

FIC $>4$ antagonistic effect

FIC: fractional inhibitory concentration

$$
\begin{aligned}
\text { FIC }= & (\text { MIC combination A/MIC Alone } \mathrm{A}) \\
& +(\text { MIC combination B } / \text { MIC Alone } \mathrm{B})
\end{aligned}
$$

Cytotoxicity of GO, Flu and GO/Flu against SW480 cell line

Cytotoxicity of GO, Flu, and GO/Flu compounds were evaluated through MTT assay against SW480 cell line (Roudbary et al. 2015). Briefly, $100 \mu \mathrm{L}$ of RPMI containing $1 \times 10^{3}$ cell suspension was seeded in each well of microtiter plates (tissue culture grade, 96 wells, flat bottom, Corning, USA). After $24 \mathrm{~h}, 100 \mu \mathrm{L}$ of Flu (16 $\mu \mathrm{g} /$ $\mathrm{mL}), \mathrm{GO}(800 \mu \mathrm{g} / \mathrm{mL})$, and $\mathrm{GO} / \mathrm{Flu}(400 / 9 \mu \mathrm{g} / \mathrm{mL})(\mathrm{GO}$ at $400 \mu \mathrm{g} / \mathrm{mL}$ concentration and Flu at $9 \mu \mathrm{g} / \mathrm{mL}$ concentration) were added and incubated in $5.0 \% \mathrm{CO}_{2}$ incubator in $37^{\circ} \mathrm{C}$ for $24 \mathrm{~h}$. The cell suspension without any treatment was considered as the control group. The array was performed triplicate in each experiment. After the incubation time, $20 \mu \mathrm{L}$ of MTT (3-(4,5-dimethylthiazol-2yl)-2,5-diphenyltetrazolium bromide) (Sigma, $5 \mathrm{mg} / \mathrm{mL}$ in PBS) was added in each well. After $4 \mathrm{~h}$ incubation under the same condition, the supernatant was removed and $30 \mu \mathrm{L}$ dimethyl sulfoxide (DMSO) was added to each well. When the purple formazan crystals were dissolved completely after 10 min of mild shaking, the spectrophotometrical absorbance was measured in microtiter plate (state fax 2100 microplate reader) reader at $590 \mathrm{~nm}$ wavelength. The cell viability was calculated using the following formula:

Cell viability $=$ OD test/OD control (absorption of positive control (SW480 cells and medium) $\times 100$

\section{Adhesion assays}

To evaluate the effect of GO/Flu compound on Candida ability to adherence to the SW480 cells, fungal cells were treated with different concentrations of Flu $(16 \mu \mathrm{g} / \mathrm{mL})$, GO $(800 \mu \mathrm{g} / \mathrm{mL})$ and $\mathrm{GO} / \mathrm{Flu}(400 / 9 \mu \mathrm{g} / \mathrm{mL})$ and were co-cultured with SW480 cells. For this purpose, $1 \times 10^{3}$ fungal suspension and $100 \mu \mathrm{L}$ of SW $4801 \times 10^{3}$ were prepared in a Dulbecco's Modified Eagle Medium (DMEM) medium and seeded in microplate wells, and were then incubated at $37{ }^{\circ} \mathrm{C}$ for $24 \mathrm{~h}$. The supernatant containing non-adherent Candida cells was removed and $10 \mu \mathrm{L}$ of the suspension containing adherent Candida cells was cultured on Sabouraud dextrose agar (SDA, Merck). After $24 \mathrm{~h}$ incubation at $35^{\circ} \mathrm{C}$, the colony count was performed (Silva-Dias et al. 2015). Each experiment was performed at least three times.

\section{DNA fragmentation assay}

For determining DNA fragmentation, C.albicans was treated with MIC concentration of GO/Flu compound and then the genomic DNA of treated and non-treated 
C.albicans was extracted using phenol/chloroform reagent, glass bead, and lysis buffer, as described previously (Roudbary et al. 2012).

The digested fragments were electrophoresed through $1.8 \%$ agarose gel and then were visualized using ethidium bromides staining.

\section{Statistical analysis}

MTT tests were analyzed using one-way analysis of variance (ANOVA) and Tukey tests using SPSS software, version 20 (SPSS, Chicago, IL, USA). Each experiment was performed at least three times. Variations in the colony count among treatment groups in adhesion assays were assessed using the Pearson's Chi square or Fisher's exact test. Variations in the colony count between the studied groups were assessed using the Mann-Whitney $U$ test. A $p$ value of $\leq 0.05$ was considered to be statistically significant.

\section{Results and discussion}

\section{Characterization of GO and GO/Flu compound}

The GO Raman spectrum confirmed $\mathrm{G}$ and D bands at 1615 and $1384 \mathrm{~cm}^{-1}$, respectively (Fig. 1). In a Raman spectrum for carbon materials, the $\mathrm{G}$ band is a characteristic feature of the graphitic layers and corresponds to the tangential vibration of the carbon atoms, while the D band corresponds to the disordered carbon or defective graphitic structures. The integral intensity ratio of these two peaks scales with the degree of graphitic ordering of the carbons. According to the reference peak, D and G bands indicated the GO structure was regular and consistent.

To confirm the structure of GO, GO/Flu, and Flu loading GO with CPTES, FTIR assay was carried out. In the functional $\mathrm{GO}$, the groups are $\mathrm{OH}$ at $3500 \mathrm{~cm}^{-1}, \mathrm{C}-\mathrm{O}$ at $1084 \mathrm{~cm}^{-1}, \mathrm{C}=\mathrm{O}$ at $1726 \mathrm{~cm}^{-1}$, and $\mathrm{C}=\mathrm{C}$ at $1627 \mathrm{~cm}^{-1}$. Moreover, GO-Cl indicated that $\mathrm{SiOCH}_{3}$ group of CPTES and $\mathrm{OH}$ group of $\mathrm{GO}$ were combined successfully and the methyl group was deleted. In addition, O of GO with Si of the linker produced SiOSi (the peak is represented at $1108 \mathrm{~cm}^{-1}$ ). The GO/Flu combination showed 1592 and 1264 peaks that were made of $\mathrm{C}-\mathrm{N}$ in $\mathrm{GO}$ and $\mathrm{C}-\mathrm{F}$ of Flu groups, respectively. The FTIR spectra of GO, GO-Cl, and GO/Flu compound are shown in Fig. 2. The results showed that GO with a suitable plate structure have hydrophilic, hydroxyl, and acidic $(\mathrm{C}=\mathrm{C}, \mathrm{C}=\mathrm{O}, \mathrm{C}-\mathrm{O}, \mathrm{O}-\mathrm{H})$ groups. Therefore, this substrate was approved as a proper carrier with antifungal activity.

\section{Confirmation of Flu loading on GO-Cl}

The total amount of Flu that loaded on GO was determined to be $53.42 \%$ by the calibration curve of Flu. The amount of Flu loaded on GO was approximately half of the total Flu used in the combination $(42.93 \mu \mathrm{g} / \mathrm{mL})$ (Fig. 3).

\section{Antifungal activity of GO, Flu and GO/Flu}

MICs of GO and Flu against the C.albicans were $800 \mu \mathrm{g} / \mathrm{mL}$ and $16 \mu \mathrm{g} / \mathrm{mL}$, respectively. The MIC of GO/Flu compound

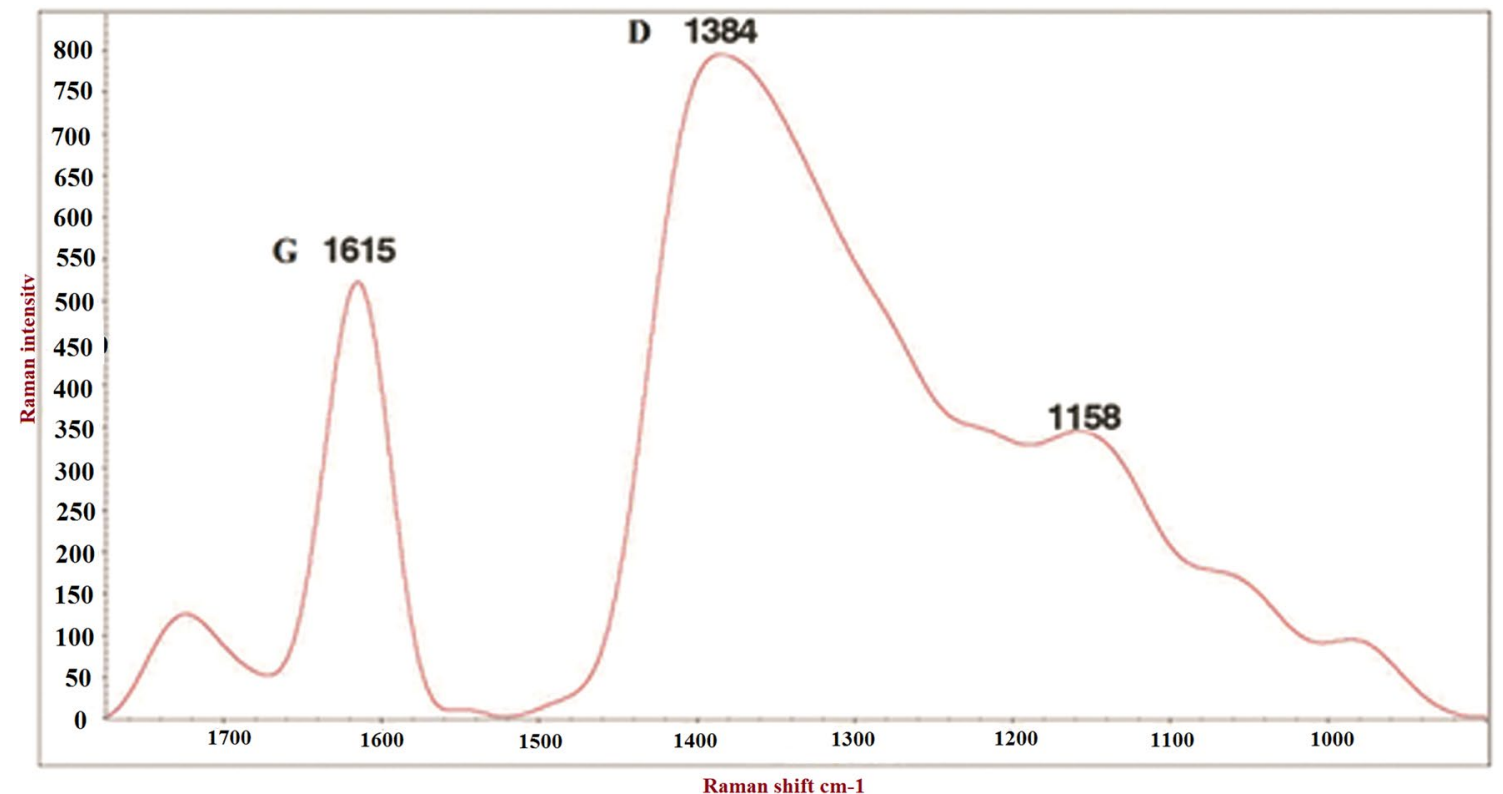

Fig. 1 Raman spectrum of GO in the range of $1000-1700 \mathrm{~cm}^{-1}$ 


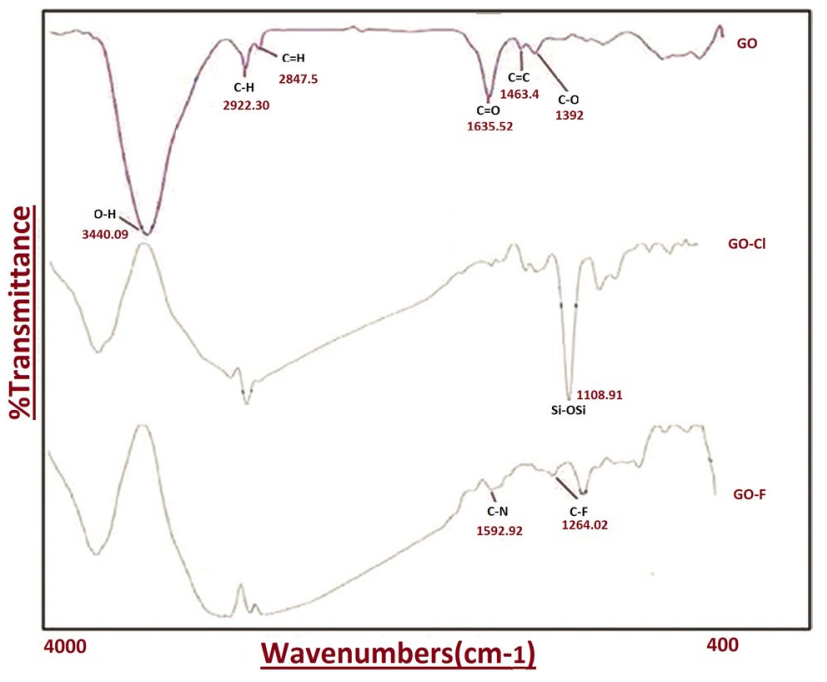

Fig. 2 FTIR spectra of GO, GO/Flu and GO/Flu compound

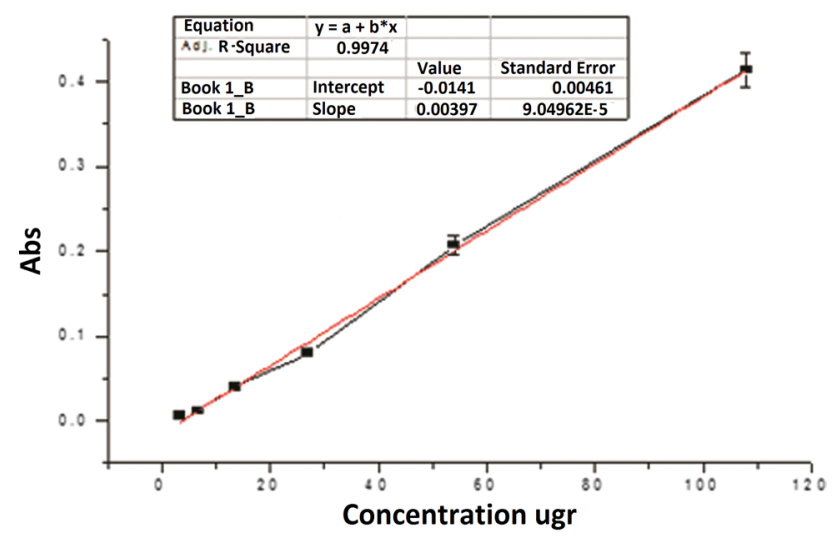

Fig. 3 Flu calibration in DMF with $\mathrm{pH} 7.4$

was $400 / 9 \mu \mathrm{g} / \mathrm{mL}$, while $\mathrm{GO}$ at $400 \mu \mathrm{g} / \mathrm{mL}$ concentration and Flu at $9 \mu \mathrm{g} / \mathrm{mL}$ concentration showed a high synergistic effect $(\mathrm{FIC}=1)$. Based on the MIC findings, the antifungal properties of GO were remarkable. It could be postulated that interaction of hydrophilic feature GO and hydrophobic Candida cell wall has increased. The MIC of GO/Flu compound indicated that its antifungal activity is less than the commercial Flu. This decrease at MIC concentration may be related to the increased release of Flu in the medium. The antifungal properties of GO may be related to some probable mechanisms. First, the sharp edges of the plates affect the cell membrane and lead to the lysis of the cell. Second, through chemical oxidation, the membrane pump disrupts the cell and eventually leads to fungal cell splitting as well as reactive oxygen species (ROS) production causing cell death (Buzea et al. 2007). However, the main mechanism of nanomaterials exploitation is not well known yet, while various in in vivo and in vitro studies suggest that they are able to produce ROS and thus contribute to the accumulation of intracellular calcium, activation of transcription factors, and changes in cytokines (Uusitalo and Hempel 2012). Previous studies are in agreement with our findings that directed the effect of GO on fungi and bacteria with possible mechanisms of action. Chao Li et al. (2013) explored the antifungal activity (AgNPs-CNSS) against $C$.albicans and $C$. tropicalis where MIC GO containing nanosilver particles was significantly less than silver (Li et al. 2013).

Johnny Chen et al. (2013) examined the mechanism of interaction of GO with $F$. graminearum and $F$. oxysporum cell wall which showed that GO disrupted the cell membrane and resulted in electrolyte leakage (Chen et al. 2014). Azimi et al. evaluated the antimicrobial activity of nanoparticles of GO functionalized with hydrophilic chlorophyllin extracted from spinach leaves against Escherichia coli (Azimi et al. 2014). Savganfrak et al. (2012) investigated the fungicidal properties of revived rGO, GO on A. nigger, A. oryzae, F. oxysporum and reported the IC50 of about $100 \mu \mathrm{g} / \mathrm{mL}$ (Sawangphruk et al. 2012).

\section{In vitro release of Flu}

The release of Flu and Flu from GO/Flu compound in a PBS medium ( $\mathrm{pH}$ 7.4) was evaluated. Flu calibration chart was prepared in PBS. Then, the concentrations were evaluated according to the calibration chart. The results displayed that the amount of Flu alone released after 6 min was 39.82\% and after 45 min was $72.42 \%$, while the release of Flu from $\mathrm{GO} /$ Flu was $12.65 \%$ after $6 \mathrm{~min}$ and $32.58 \%$ after $45 \mathrm{~min}$ (Fig. 4). Flu was released from GO/Flu to provide the minimum amount needed for the effectiveness of synergism on Candida albicans.

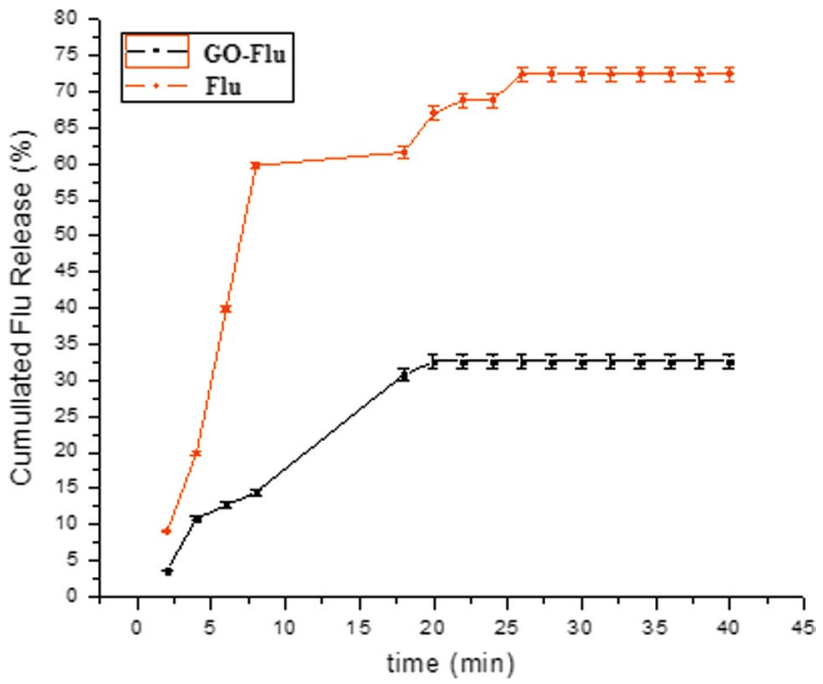

Fig. 4 The rate of Flu release from GO/Flu compared to commercial Flu in PBS buffer at $\mathrm{pH}=7.4$ 


\section{MTT-based cytotoxicity}

GO/Flu showed a dose-dependent manner on the cell viability of SW480 cell line and much less toxicity compared to $\mathrm{GO}$ and Flu. The cell viability was reduced to $20 \%$ for cells treated with GO at $800 \mu \mathrm{g} / \mathrm{mL}$ and to $46 \%$ for Flu treatment cells at $16 \mu \mathrm{g} / \mathrm{mL}$ concentration (Fig. 5). The viability of SW480 cells against Flu and GO is shown in Fig. 3a, b, respectively. Our findings showed that the toxic activity of agents was dose-dependent. Notably, at high concentrations of GO and Flu, there was a significant cell death, while at lower concentrations, a minor cytotoxicity was detected; thus, the difference between groups was significant $(P<0.05)$. Interestingly, GO exhibited higher cell toxicity than Flu; nevertheless, the toxicity decreased significantly in GO/Flu-treated cells compared to the other group. In
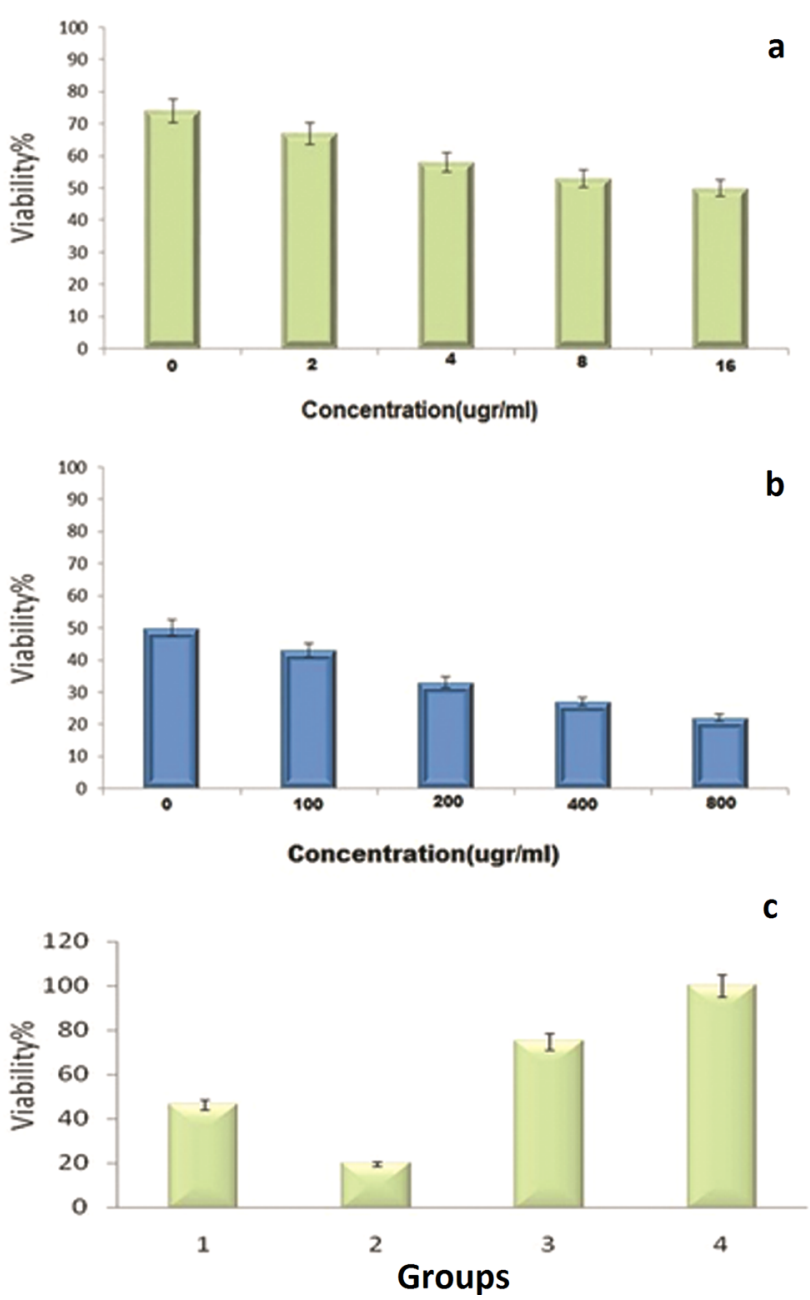

Fig. 5 a The viability of SW480 cells treated with commercial Flu at different concentrations $(0,2,4,8$ and $16 \mu \mathrm{g} / \mathrm{mL})$. b The viability of SW480 cells treated with different concentrations of GO. $\mathbf{c}$ The comparison of viability of SW480 cells treated with (1) Flu (concentration $16 \mu \mathrm{g} / \mathrm{mL})$; (2) GO $(800 \mu \mathrm{g} / \mathrm{mL})$;(3) GO/Flu compound (400-9 $\mu \mathrm{g} / \mathrm{mL}$; (4) and untreated cells (control group) contrast with our results, Yanli Chang et al. (2011) explored the toxicity of GO on A549 cell line and showed that $67 \%$ of cells survived at a concentration of $200 \mu \mathrm{g} / \mathrm{mL}$ (Chang et al. 2011). Chao $\mathrm{Li}$ (2013) also reported $60 \%$ and $20 \%$ cytotoxicity of GO-AgNPs and GO, respectively, on GES-1 at a concentration of $100 \mu \mathrm{g} / \mathrm{mL}$ using the MTT method ( $\mathrm{Li}$ et al. 2013).

\section{Adhesion assays}

As shown in Fig. 6, the lowest number of candida colonies was found in the GO/Flu group. Variations in the colony count between the studied groups were assessed using the Mann-Whitney $U$ test. Indeed, in the adhesion assays, a significant difference was found between the number of $\mathrm{Can}$ dida colonies in the Flu, GO, and GO/Flu treatment cells and the control group $(P<0.05)$. Remarkably, we found that Candida colonies treatment with GO/Flu was lower than that of GO and Flu $(P<0.05)$. It can be concluded that GO/Flu strongly inhibited Candida adhesion to SW480 cells. It may be explained that the compound affected the genes responsible for $C$. albicans attachment. It is well established that Candida attachment is the first step for inducing the pathogenesis; therefore, GO/Flu inhibits the successful adhesion of Candida to cells and can be a proper agent to prevent the Candida attachment.

\section{DNA fragmentation}

As shown in Fig. 7, the DNA fragmentation test indicated that GO/Flu notably degraded the Candida DNA when compared to Flu, GO, and control groups. The result of DNA fragmentation showed that DNA of $C$. albicans treated with $\mathrm{GO} /$ Flu was much more degraded than other treated groups (Kim et al. 2011; Singh et al. 2009; Pisanic et al. 2007). Taken together, the obtained results disclosed the proper

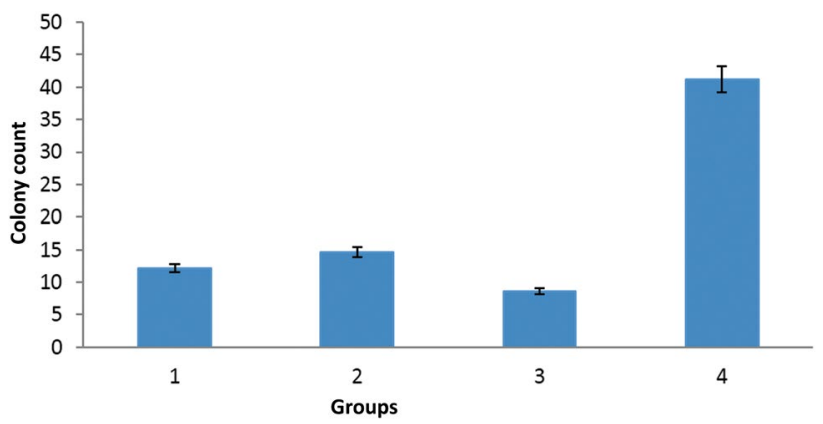

Fig. 6 SW480 cells were co-cultured with Candida that treated by Flu, GO, GO/Flu previously. The supernatant contains non-adherent Candida cells were removed, subsequenty adherent Candida cells cultured on SDA medium. 1: Flu (concentration $16 \mu \mathrm{g} / \mathrm{mL}$ ); 2: GO $(800 \mu \mathrm{g} / \mathrm{mL}) ; 3$ : GO/Flu (400-9 $\mu \mathrm{g} / \mathrm{ml})$ with $\mathrm{GO}$ at $400 \mu \mathrm{g} / \mathrm{ml}$ concentration and Flu at $9 \mu \mathrm{g} / \mathrm{ml}$ concentration); 4: control 
Fig. 7 Electrophoresis image from genomic DNA Candida in different treatment groups. (1, 2) Candida non-treatment, (3) marker $100 \mathrm{bp}$, (4) GO treatment, (5) Flu treatment, (6) GO/ Flu compound treatment, (7) DNA treated with DNase

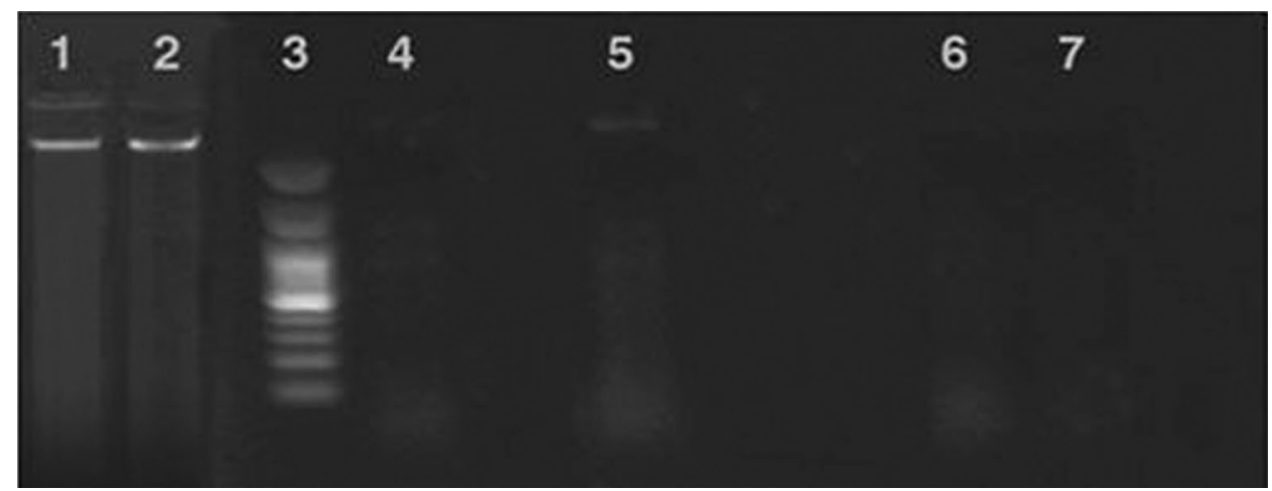

anti-Candida properties of GO/Flu. Furthermore, this compound has a low cytotoxicity effect on the cell line which ensures its safety regarding human cells.

\section{Conclusion}

The obtained findings suggest that the synthesized GO/Flu compound exhibits appropriate antifungal activity against $C$. albicans and that its capacity had been increased with synergistic effect. As this compound showed no significant toxicity against SW480 cells, therefore it is noticed as a safe agent against human cells. Collectively, this compound could be used as a proper candidate for a therapeutic approach against candidiasis as well; however, a comprehensive in vitro and in vivo study is required in the future.

Funding This research is financially supported by Tarbiat Modares University.

\section{Compliance with ethical standards}

Conflict of interest The authors have no conflict of interest.

Ethical approval This article does not contain any studies with human participants or animals performed by any of the authors.

Open Access This article is distributed under the terms of the Creative Commons Attribution 4.0 International License (http://creativeco mmons.org/licenses/by/4.0/), which permits unrestricted use, distribution, and reproduction in any medium, provided you give appropriate credit to the original author(s) and the source, provide a link to the Creative Commons license, and indicate if changes were made.

\section{References}

Akhavan O, Ghaderi E (2010) Toxicity of graphene and graphene oxide nanowalls against bacteria. ACS Nano 4(10):5731-5736. https:// doi.org/10.1021/nn101390x
Alizadeh F, Khodavandi A, Zalakian S (2017) Quantitation of ergosterol content and gene expression profile of ERG11 gene in fluconazole resistant Candida albicans. Curr Med Mycol 3:13-19. https://doi.org/10.29252/cmm.3.1.13

Allen MJ, Tung VC, Kaner RB (2010) Honeycomb carbon: a review of graphene. Chem Rev 110(1):132-145. https://doi. org/10.1021/cr900070d

Azimi S, Behin J, Abiri R, Rajabi L (2014) Synthesis, characterization and antibacterial activity of chlorophyllin functionalized graphene oxide nanostructures. Sci Adv Mat 11:771-781. https ://doi.org/10.1166/sam.2014.1767

Buzea C, Pacheco I, Robbie K (2007) Nanomaterials and nanoparticles: sources and toxicity. Biointer Phases. 2:17-71. https:// doi.org/10.1116/1.2815690

Casalinuovo IA, Di Francesco P, Garaci E (2004) Fluconazole resistance in Candida albicans: a review of mechanisms. Eur Rev Med Pharmacol Sci 8:69-77 PMID:15267120

Chang Y, Yang ST, Liu JH, Dong E, Wang Y, Cao A, Liu Y, Wang H (2011) In vitro toxicity evaluation of graphene oxide on A549 cells. Toxico Lett 200:201-210. https://doi.org/10.1016/j.toxle t.2010.11.016

Charlier C, Hart E, Lefort A, Ribaud P, Dromer F, Denning DW, Lortholary O (2006) Fluconazole for the management of invasive candidiasis: where do we stand after 15 years. J Antimicrob Chemother 57:384-410. https://doi.org/10.1093/jac/dki473

Chaudhary K (2013) Graphene its synthesis and its application in anti cancer drug delivery. Int J Sci and Res (IJSR). 4:741-744

Chen J, Peng H, Wang X, Shao F, Yuan Z, Han H (2014) Graphene oxide exhibits broad spectrum antimicrobial activity against bacterial phytopathogens and fungal conidia by intertwining and membrane perturbation. Nanoscale. 6:1879-1889. https:// doi.org/10.1039/c3nr04941h

Claudia S, Carlucci A, Bregni C (2010) Study of in vitro drug release and percutaneous absorption of fluconazole from topical dosage forms. AAPS Pharm Sci Tech. 11:986-993. https://doi. org/10.1208/s12249-010-9457-1

Cong HP, He JJ, Lu Y, Yu SH (2010) Water-soluble magnetic-functionalized reduced graphene oxide sheets: in situ synthesis and magnetic resonance imaging applications. Small 6(2):169-173. https://doi.org/10.1002/smll.200901360

Haubner K, Murawski J, Olk P, Eng LM, Ziegler C, Adolphi B, Jaehne E (2010) The route to functional graphene oxide. Chemo physchem 11:2131-2139. https://doi.org/10.1002/cphc.20100 0132

Kanafani ZA, Perfect JR (2008) Resistance to antifungal agents: mechanisms and clinical impact. Clin Infect Dis 46(1):120-128. https://doi.org/10.1086/524071

Khan ZU, Chandy R, Metwali KE (2003) Candida albicans strain carriage in patients and nursing staff of an intensive care unit: 
a study of morphotypes and resistotypes. Mycoses 46(1112):479-486 PMID:14641621

Kim J, Lee N, Kim B, Rhee W, Yoon S, Hyeon T, Park T (2011) Enhancement of neurite outgrowth in PC12 cells by iron oxide nanoparticles. Biomaterials 32:2871-2877. https://doi. org/10.1016/j.biomaterials.2011.01.019

Li C, Wang X, Chen F, Zhang C, Zhi X, Wang K, Cui D (2013) The antifungal activity of graphene oxide-silver nanocomposites. Biomaterials 34:3882-3890. https://doi.org/10.1016/j.biomateria 1s.2013.02.001

Liu S, Zeng TH, Hofmann M, Burcombe E, Wei J, Jiang R, Kong J, Chen Y (2011) Antibacterial activity of graphite, graphite oxide, graphene oxide, and reduced graphene oxide: membrane and oxidative Stress. ACS Nano 5:6971-6980. https://doi.org/10.1021/ nn202451x

Pasricha R, Gupta S, Joshi AG, Bahadur N, Haranath D, Sood KN, Singh S, Singha S (2012) Directed nanoparticle reduction on graphene. Mater Today 15:118-125. https://doi.org/10.1016/S1369 -7021(12)70047-0

Pisanic TR, Blackwell JD, Shubayev VI, Fiñones RR, Jin S (2007) Nanotoxicity of iron oxide nanoparticle internalization in growing neurons. Biomaterials 28:2572-2581. https://doi.org/10.1016/j. biomaterials.2007.01.043

Roudbary M, Roudbarmohammadi SH, Bakhshi B, Farhadi Z (2012) Relation of ALS 1 and ALS3 genes and fluconazole resistance in Candida albicans isolated from vaginal candidacies. Int J Mole Clinic Microbiol 2:170-174

Roudbary M, Daneshmandi S, Hajimoradi M, Roudbarmohammadi SH, Zuhair MH (2015) Immunomodulatory effect of $\beta$-glucan on peritoneal macrophages of BABL/c mice. Polish Journal of Microbiology 64:175-179

Sawangphruk M, Srimuk P, Chiochan P, Sangsri T (2012) Synthesis and antifungal activity of reduced grapheme oxide nanosheets. Carbon 50:5156-5161. https://doi.org/10.1016/j.carbo n.2012.06.056
Shen H, ZhangL Liu M, Zhang Zh (2012) Biomedical Applications of Graphene. Theranostics 2:283-294. https://doi.org/10.7150/ thno. 3642

Silva-Dias A, Miranda I, Branco J, Monteiro-Soares M, Pina-Vaz C, Rodrigues A (2015) Adhesion, biofilm formation, cell surface hydrophobicity, and antifungal planktonic susceptibility: relationship among Candida spp. Front Microbiol. 6:205. https://doi. org/10.3389/fmicb.2015.00205

Singh N, Manshian B, Jenkins G, Griffiths S, Williams P, Maffeis T, Wright CH, Doak Sh (2009) Nano genotoxicology: the DNA damaging potential of engineered nanomaterials. Biomaterials 30:3891-3914. https://doi.org/10.1016/j.biomaterials.2009.04.009

Stankovich S, Dikin DA, Piner RD, Kohlhaas KA, Kleinhammes A, Jia Y, Yue WU, Son Binh TS (2007) Synthesis of graphenebased nanosheets via chemical reduction of exfoliated graphite oxide. Carbon 45:1558-1565. https://doi.org/10.1016/j.carbo n.2007.02.034

Uusitalo LM, Hempel N (2012) Recent advances in intracellular and in vivo ROS sensing: focus on nanoparticle and nanotube applications. Int J Mol Sci 13(9):10660-10679. https://doi.org/10.3390/ ijms 130910660

Weber K, Sohr R, Schulz B, Fleischhacker M, Ruhnke M (2008) Secretion of $\mathrm{E}, \mathrm{E}$-farnesol and biofilm formation in eight different candida species. Antimicrob Agents Chemother 52:1859-1861. https ://doi.org/10.1128/AAC.01646-07

William S, Jr Hummers, Offeman Richard E (1958) Preparation of graphitic oxide. J Am Chem Soc 80:1339. https://doi.org/10.1021/ ja01539a017

Yang K, Zhang S, Zhang GX, Sun XM, Lee ST, Liu Z (2012) Graphene in mice: ultrahigh in vivo tumor uptake and efficient photothermal therapy. Nano Lett 10:3318-3323. https://doi.org/10.1021/nl100 996u

Publisher's Note Springer Nature remains neutral with regard to jurisdictional claims in published maps and institutional affiliations. 